\title{
Subphrenic abscess secondary to cervical abscess and fasciitis from dental focus: case report
}

\author{
Caroline Petersen da Costa Ferreira ${ }^{1 *} \mathbb{D}$, Marianne Yumi Nakai ${ }^{2}$, Caroline Schmiele Namur ${ }^{3}$, Lucas Ribeiro Tenório ${ }^{2}$ \\ and Antonio José Gonçalves²
}

\begin{abstract}
Background: Cervical fasciitis is a group of severe infections with high morbimortality. Reports in the literature of patients with cases evolving with mediastinal dissemination of deep cervical abscess are common. However, cases of abdominal dissemination by contiguity are much rarer.

Case presentation: A 34-year-old Caucasian man presented to the emergency department with a 15-day history of left neck edema, local pain, and fever. Seventeen days prior to presentation, he had undergone odontogenic surgical treatment in a dental clinic. Laboratory examinations did not show meaningful changes. He underwent computed tomography of the neck, thorax, and abdomen, which showed evidence of left collection affecting the retromandibular, submandibular, parapharyngeal, vascular, and mediastinal spaces, bilateral pleural effusion, right subphrenic collection and a small amount of liquids between intestinal loops. A cervical, thoracic, and abdominal surgical approach at the same surgery was indicated for odontogenic cervical abscess, descending necrotizing mediastinitis, and subphrenic abscess. The patient remained in the intensive care unit for three days, and he was discharged on the 22nd day after surgery with no drains and no tracheostomy. His outpatient discharge occurred after 6 months with no sequelae.

Conclusions: Aggressive surgical treatment associated with antibiotic therapy has been shown to be effective for improving the clinical course of cervical fasciitis. Despite the extension of the infection in our patient, a surgical approach of all infectious focus associated with a broad-spectrum antibiotic therapy led to a good clinical evolution and has significant implications for aggressive treatment.
\end{abstract}

Keywords: Cervical fasciitis, Mediastinitis, Odontogenic abscess

\section{Background}

Cervical fasciitis (CF) is a group of bacterial infections, usually of odontogenic or amygdala origin, characterized by necrosis of the fascia and subcutaneous cellular tissue of the neck $[1,2]$. It is a rare disease with high morbimortality rates. It may evolve with mediastinitis, especially in patients with comorbidities and immunosuppression [3, 4]. Approximately $46 \%$ of the patients with CF arising with mediastinitis show at least one of the risk factors: diabetes mellitus, atherosclerosis, alcohol abuse, kidney failure, neoplasia, intravenous drug abuse, or postpartum status [5-7].

\footnotetext{
* Correspondence: cacapetersen@gmail.com

${ }^{1}$ Emergence Department, Irmandade da Santa Casa de Misericórdia de São

Paulo, São Paulo, Brazil

Full list of author information is available at the end of the article
}

Mediastinitis occurs through infection propagation (fasciitis) in the deep spaces of the neck that continue with mediastinal fascia and the pericardium. Usually, the clinical scenario in this case is severe sepsis or septic shock $[8,9]$.

CF diagnosis is based on a combination of clinical presentation and imaging. It usually involves polymicrobial infection, both aerobic and anaerobic [2]. Early diagnosis and precise treatment of this pathology in its early stage (before clinical signs of deterioration) are critical in the prognosis of these patients [10].

This report describes a case of a rare disease with an unusual presentation. It is worth highlighting the fact that despite the rarity, it is a serious condition with high potential for morbidity and mortality. Often its diagnosis and treatment are delayed because of the difficulty in 
identifying the symptoms and the severity of the case. Several chest complications of deep cervical abscess [710] have been reported in the literature, but abdominal involvement is uncommon. Some cases of liver abscess through hematogenic dissemination [11-13] from CF have also been reported. However, abdominal dissemination by contiguity (such as the case we report herein) is much rarer. It occurred in one case of retroperitoneal localization [14] and another one with abdominoperineal extension [15].

With this information in mind, it is important to understand that it is a unique presentation of a severe condition that usually presents with a fast progression to sepsis with a high mortality rate. The identification of this kind of dissemination can prevent an unfavorable outcome by giving the physician's team the whole picture of the case, allowing them to intervene at all sites of the infection.

\section{Case presentation}

A 34-year-old Caucasian man presented to the emergency department with a 15-day history of left neck edema, local pain, and fever. He was in good general condition, awake, lucid, oriented but discretely dyspneic. He had trismus (70\%); a painful, warm, red, hard left neck bulging of $10 \mathrm{~cm}$ in length without signs of fluctuation; fever (temperature $38.8^{\circ} \mathrm{C}$ ); ventilator-dependent pain in the right hemithorax; respiratory rate of 23 breaths/min; pulse rate of 100 beats/min, and abdominal discomfort in the right hypochondrium. His blood pressure was within normal range at $110 / 70 \mathrm{mmHg}$. He had no alterations in cardiac auscultation and a reduced vesicular murmur at the right hemithorax. His abdomen was discretely distended, and he had considerable pain in the right hypochondrium. His Murphy's sign was negative, he had no sign of peritonitis. He did not present with any neurological symptoms.

The patient and his wife and children lived in a small house with a monthly income of approximately 410 dollars. There was no record of a permanent job, but he formerly worked in construction as a bricklayer. He had no significant past medical history, but he reported daily smoking (20 cigarettes/day) for 20 years and alcohol consumption of $500 \mathrm{ml}$ of distillate drinks on a daily basis for 10 years. He denied illicit drug consumption.

Seventeen days prior to presentation, he had undergone odontogenic surgical treatment in a dental clinic. He received oral amoxicillin $500 \mathrm{mg} / 8 \mathrm{~h}$ two days prior to the dental procedure, and after that, he received it for five more days with dipyrone $(1 \mathrm{~g} / 6 \mathrm{~h})$ and nimesulide $(100 \mathrm{mg} / 12 \mathrm{~h})$. After the dental procedure, seven days before his admission to our unit, he went to another emergency room (ER) with the same symptoms, and there he received empirical intravenous antibiotic therapy (ciprofloxacin $400 \mathrm{mg} / 12 \mathrm{~h}$ ) for seven days. Realizing that he was not improving, he left the first ER and presented to our hospital.

Upon his admission to our hospital, we started to manage the sepsis with an intravenous isotonic saline solution and empirical broad-spectrum antibiotics $(1000 \mathrm{ml}$ of $0.9 \%$ sodium chloride solution + ceftriaxone $1 \mathrm{~g} / 12 \mathrm{~h}+$ clindamycin $600 \mathrm{mg} / 6 \mathrm{~h}$ ). We planned antibiotic administration for 21 days, and it was given as intravenous dipyrone $(1 \mathrm{~g} / 6 \mathrm{~h})$ for fever and tramadol $(100 \mathrm{mg} / 8 \mathrm{~h})$ for pain. Laboratory examinations did not show meaningful changes (Table 1). The patient underwent serological screening to rule out possible causes of immunodeficiency (Table 2), and blood cultures were collected. He underwent cervicothoracoabdominal computed tomography (CT) (Figs. 1 and 2). CT of the neck demonstrated soft-tissue infiltration and edema of the muscular tissue; left retromandibular, submandibular, parapharyngeal, and vascular space collections; and another left upper encapsulated fluid mediastinal collection. CT of the thorax and abdomen demonstrated bilateral pleural effusion, right subphrenic collection, and a small amount of liquid between intestinal loops.

Initially, based on these data, it was concluded that the patient had deep neck space infection (with involvement of the cervical fascia) from a dental focus, descending necrotizing mediastinitis, and subphrenic abscess; therefore, the patient underwent cervical, thoracic, and abdominal aggressive operative drainage. After bronchoscopic intubation without muscle blockers, the surgery was started by left cervicotomy, evidencing an abscess cavity in the submandibular and retromandibular spaces in addition to a small amount of thick liquid in left

Table 1 Laboratory examinations upon admission

\begin{tabular}{lll}
\hline Laboratory examinations & Admission values & Reference values \\
\hline Hemoglobin & $9.7 \mathrm{~g} / \mathrm{dl}$ & $14-18 \mathrm{~g} / \mathrm{dll}[17]$ \\
Leukocytes & $10,800 / \mu l$, no deviations & $4,000-11,000 / \mu l[17]$ \\
C-reactive protein & $4.4 \mathrm{mg} / \mathrm{dl}$ & $0.8 \mathrm{mg} / \mathrm{dl}$ or less ${ }^{\mathrm{a}}[17]$ \\
Creatinine & $0.6 \mathrm{mg} / \mathrm{dl}$ & $0.7-1.5 \mathrm{mg} / \mathrm{dl}[17]$ \\
Urea & $17 \mathrm{mg} / \mathrm{dl}$ & $8-20 \mathrm{mg} / \mathrm{dl}[17]$ \\
\hline
\end{tabular}

${ }^{\mathrm{a} C}$-reactive protein: low risk, $<1.0 \mathrm{mg} / \mathrm{L}$; average risk, 1.0-3.0 mg/L; high risk, $>3.0 \mathrm{mg} / \mathrm{L}$ [16] 
Table 2 Serology

\begin{tabular}{ll}
\hline Laboratory examinations & Result \\
\hline HIV (1 and 2) & Negative \\
HTLV (1 and 2) & Negative \\
Hepatitis C serology & Negative \\
Hepatitis B serology & Negative \\
\hline
\end{tabular}

HIV Human immunodeficiency virus, HTLV Human T-cell leukemia-lymphoma virus

vascular and retropharyngeal spaces and upper mediastinum. The procedure consisted of extensive debridement and drainage of the cervical and mediastinal collection with tracheostomy to secure the airway (Fig. 3). Drainage tubes were left in place, and samples were taken for culture and an antibiogram. Afterward, a right posterolateral thoracotomy was performed, evidencing serum pleural effusion and mediastinal and pericardial thickening. Mediastinal and pleural drainage was done via large-bore chest tubes. An abdominal approach through median supraumbilical laparotomy revealed a right subphrenic abscess. After drainage of $2000 \mathrm{ml}$ of purulent secretion (Figs. 4 and 5), drainage tubes were also left in place, and samples were taken.
The following day, the patient had septic shock and needed vasoactive drugs. The antibiotic treatment was changed to intravenous piperacillin and tazobactam $4 \mathrm{~g} /$ $6 \mathrm{~h}$ and vancomycin $1 \mathrm{~g} / 12 \mathrm{~h}$.

The bacteriologic results from materials obtained from the abdomen revealed only Candida albicans. Aerobic and anaerobic liquid cultures were collected with sterile syringes in the surgical field and were stored in dry tubes for aerobic pathogens and in appropriate liquid contents for anaerobes. We don't have information about how was made the transportation of the tubes. There was no growth in the neck, pleura, and mediastinum material. The blood culture was also negative. Gram staining did not detect any bacteria. These were probably due to the patient's previous use of antibiotics. Fluconazole (400 $\mathrm{mg} / 12 \mathrm{~h}$ ) was added to the treatment.

After three days in the intensive care unit, the patient was hemodynamically stable with apparent improvement, and he was transferred to the head and neck ward. He had 21 days of antibiotic treatment (2 days of ceftriaxone $1 \mathrm{~g} / 12 \mathrm{~h}+$ clindamycin $600 \mathrm{mg} / 6 \mathrm{~h}$, 19 days of piperacillin and tazobactam $4 \mathrm{~g} / 6 \mathrm{~h}$ ) and 15 days of antifungal treatment (fluconazole $400 \mathrm{mg} / 12 \mathrm{~h}$ ), and then he was discharged from the hospital on the 22nd postoperative day, without drains or tracheostomy. His

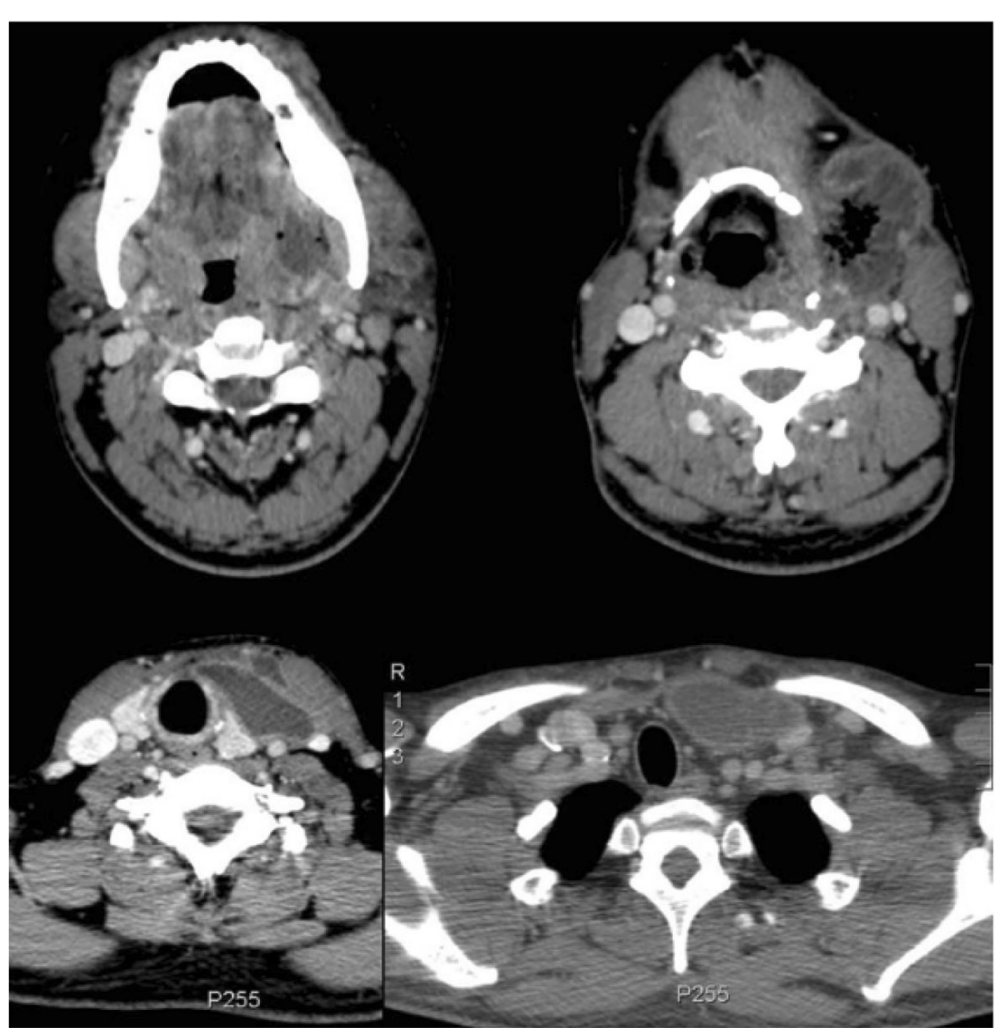

Fig. 1 Computed tomography of the neck with evidence of extension of the left collection affecting the retromandibular, submandibular, parapharyngeal, and vascular spaces, as well as the upper mediastinum 

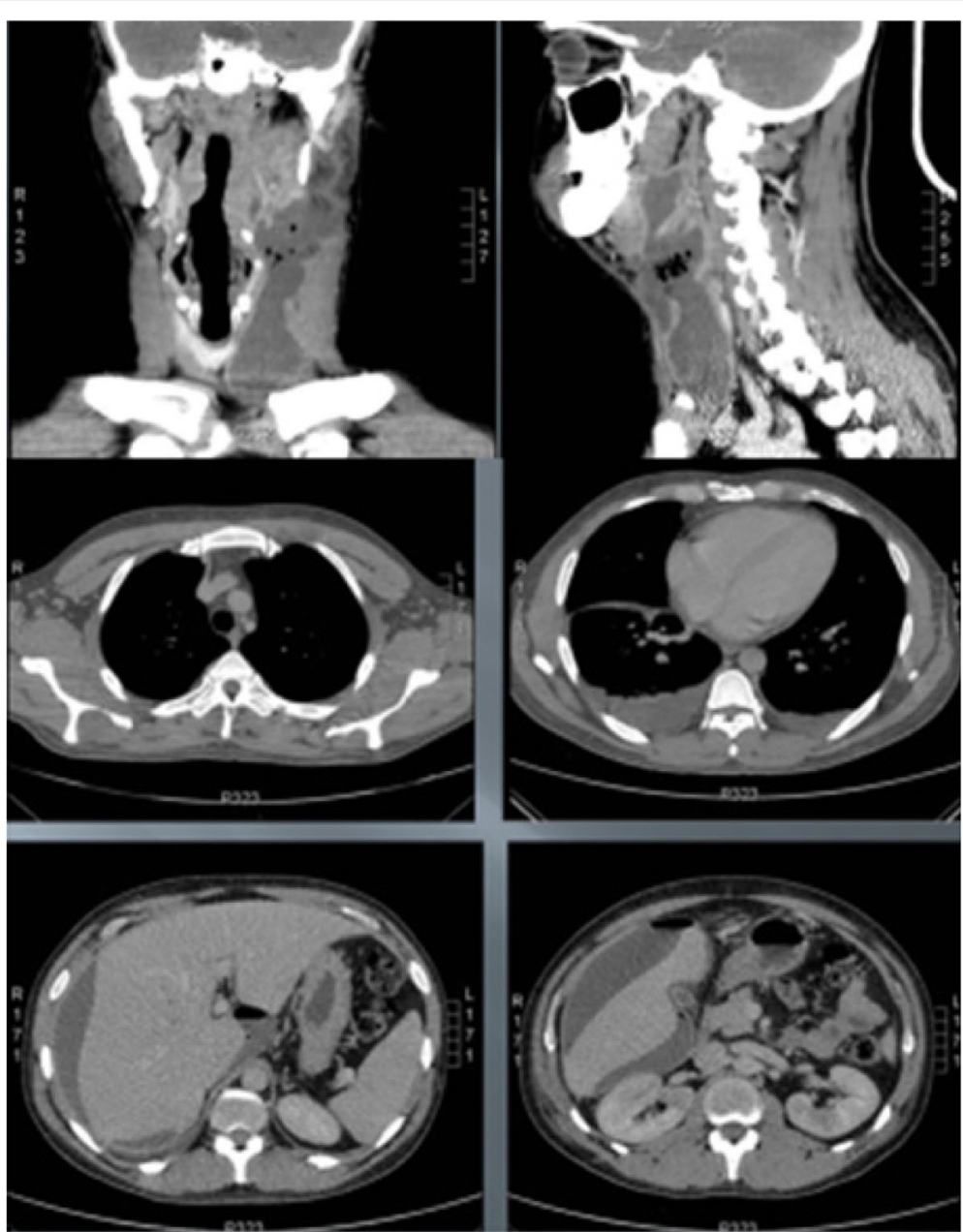

Fig. 2 Computed tomography of the neck, thorax, and abdomen showing process extension

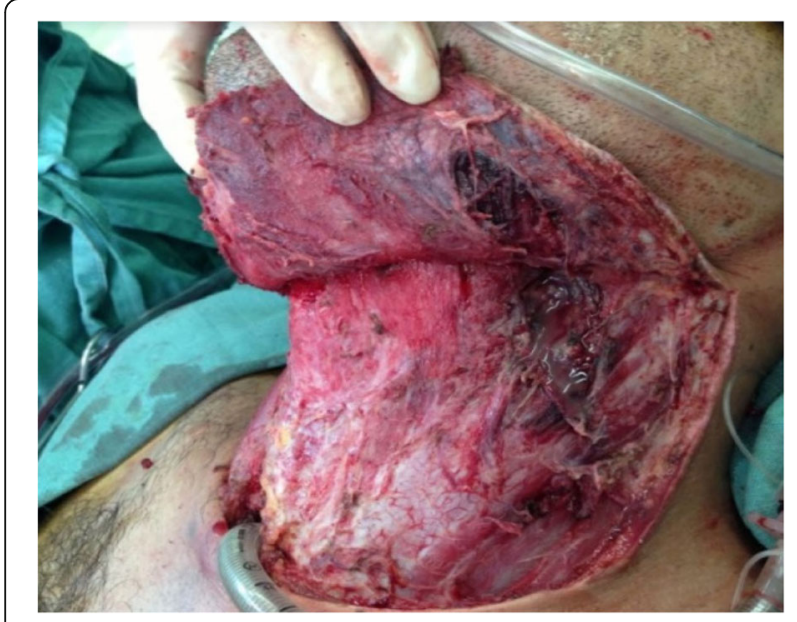

Fig. 3 Final aspect of the cervicotomy outpatient discharge occurred six months later, without any sequelae. At his last appointment, the scars had a good aspect, with no keloids or hypertrophy, and he had no complaints about swallowing, breathing, or vocal hoarseness. He was able to get back to his work with no restrictions.

\section{Discussion}

This report describes a case of a young man who, after dental treatment for periodontal infection, had an unfavorable evolution with cervical infection and progression to the thorax and abdomen. He underwent broad-spectrum antibiotic therapy in addition to the general measures for sepsis and aggressive surgical treatment with cervicotomy, thoracotomy, and laparotomy for drainage of all abscess stores. This treatment led to a good evolution and favorable outcome with discharge in a reasonably short time and return to usual activities. The peculiarity and severity of this case is a reminder that treatment of a cervical abscess should include 


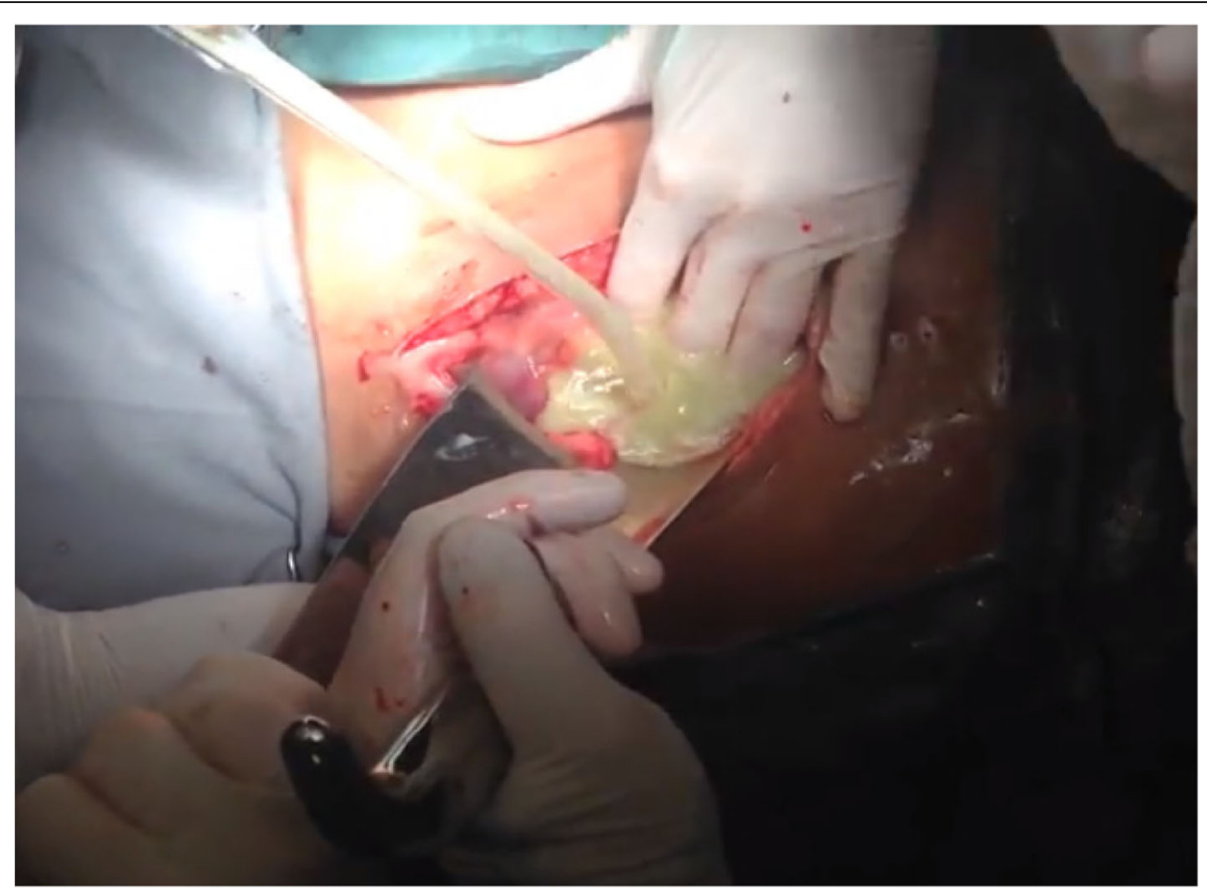

Fig. 4 Aspect of secretion after break of the capsule in the subphrenic abscess intraoperatively

intravenous broad-spectrum antibiotics and surgical drainage of the purulent collections. As highlighted before, this case report describes a rare serious disease with an unusual presentation with a high potential for a rapid course and unfavorable outcome. Most of the time, in unspecialized health units, the diagnosis and treatment can be delayed because of the difficulty in identifying the symptoms and the severity of the case. Despite the scarcity of records regarding the disease and the lack of uniformity of the therapeutic approach in different health units, there is a consensus that aggressive and early surgical treatment gives the patient the best chance of survival $[3,4]$.

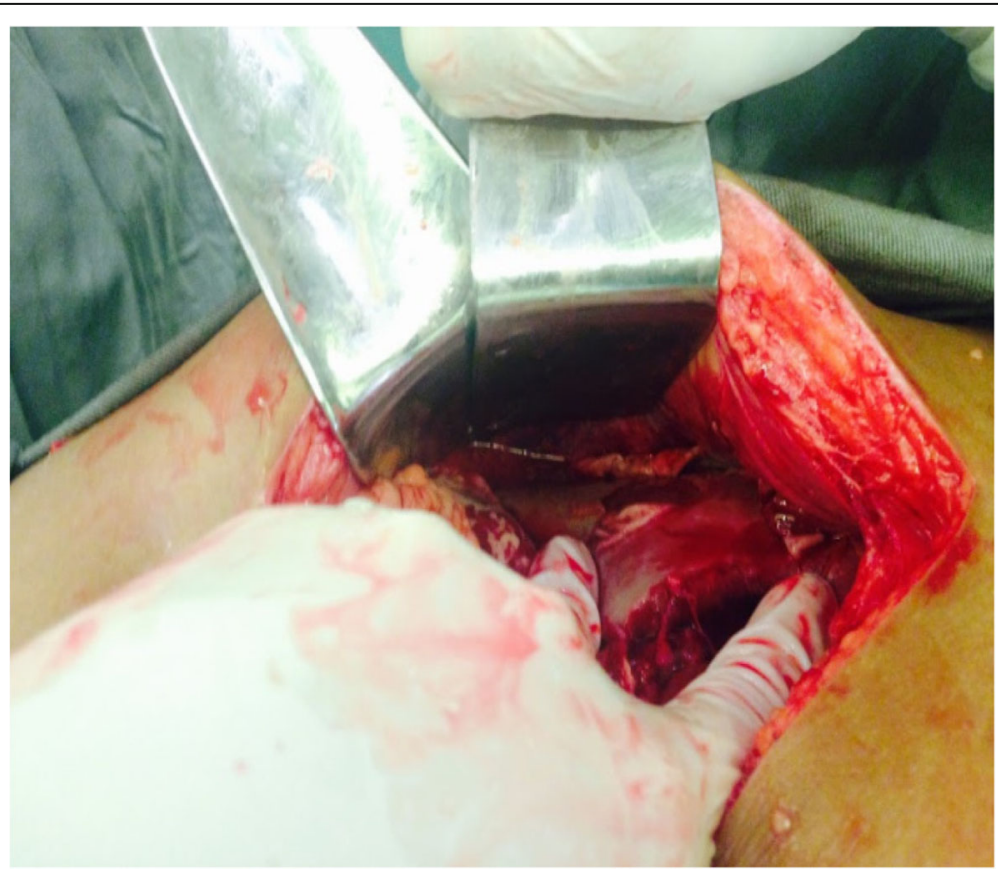

Fig. 5 After aspiration of the purulent secretion, a well-formed subphrenic abscess cavity is evidenced by the presence of fibrin 
The global literature reports several cases of mediastinal dissemination of deep cervical abscess [7-10]. Although rare, there are some cases of hepatic abscess through hematogenic dissemination [11-13]; however, abdominal dissemination by contiguity is even rarer, and it occurred in only one case of retroperitoneal localization [14] and another with abdominoperineal extension [15].

A good understanding of the cervical fascial anatomy is essential for CF diagnosis and its possible complications, because clinical presentation and dissemination are based on deep cervical spaces. The perivascular space contains the carotid artery, internal jugular vein, and vagus nerve. The prevertebral (or retrovisceral) space is divided into retropharyngeal and danger spaces by the alar fascia. Perivascular and prevertebral spaces are contiguous with the upper mediastinum and pretracheal space with the anterior mediastinum. Infections affecting such spaces show a higher chance of evolving to mediastinitis $[17,18]$.

Diagnosis may be difficult, especially with the previous use of antibiotics, where symptoms may be masked, and dissociation may be found between the clinical condition and the imaging examination. CT is vital to good therapeutic planning, being the gold standard for this evaluation [19]. The most common pathogens involved in this kind of infection in Brazil are Staphylococcus aureus and Streptococcus viridans, although most often a polymicrobial flora with anaerobic pathogens from regular oral flora is found [4].

Risk factors associated with a poor prognosis are the following: diabetes mellitus, alcohol abuse, poor oral hygiene, malnutrition, corticotherapy, improper treatment with antibiotics, and time to treatment (time between diagnosis and treatment: $6-18 \mathrm{~h}: 28.5 \%$ of mortality; time between diagnosis and treatment $>18 \mathrm{~h}$ : $42 \%$ of mortality) [19].

Surgical approach with broad cervicotomy for exploration of deep spaces, washing, and drainage associated with focus-driven antibiotic therapy should be the base of CF treatment $[18,20]$.

The airway may be a challenge in the initial approach of these patients, who often show trismus, secretion, edema, and extrinsic bulging, which can make the management of the airway difficult. Techniques such as awake orotracheal intubation under topic anesthesia of the airway, with or without bronchoscopic and awake tracheostomy under local anesthesia are the safest alternatives.

Abdominal dissemination of CF by contiguity is not common. The previous use of antibiotics, among its actions, may contain the infection to a restricted space, increasing the dissection pressure in this compartment and making it easier to propagate it by contiguity, which may be one of the factors that may have contributed to its occurrence in our patient.
In summary, CF remains a life-threatening infection. A deep understanding of the natural history of this infection and the local anatomy can save lives. Early diagnosis and surveillance with contrast-enhanced CT are essential. The extension of surgical drainage should depend on the affected spaces found by $\mathrm{CT}$ and intraoperatively.

\section{Conclusions}

Although CF is rare, it has a high rate of morbimortality if diagnosed late, owing to the involvement of deep cervical spaces and predisposition to thoracic, and abdominal dissemination with worse prognosis. Aggressive surgical treatment associated with antibiotic therapy has been shown to be effective in improving the patient's clinical condition.

This report describes a patient with a 15-day history of infection empirically treated with antibiotics, who showed cervicothoracoabdominal dissemination. Despite the infection extension, a surgical approach of all infectious focus associated with broad-spectrum antibiotic therapy led to a good clinical evolution.

\section{Abbreviations \\ CF: Cervical fasciitis; CT: Computed tomography; ER: Emergency room}

\section{Acknowledgements}

Not applicable.

Funding

Not applicable.

Availability of data and materials

Not applicable.

Authors' contributions

CPCF and MYN were the surgeons who operated on the patient. AJG took care of the patient during his recovery and is the chief of the hospital's head and neck department. LRT was responsible for collecting the data. CSN reviewed the information of the patient and was responsible for editing the manuscript. CPCF was a major contributor in writing the manuscript. All authors read and approved the final manuscript.

Ethics approval and consent to participate

Santa Casa de São Paulo Ethics and Research Committee approved this publication on 25 Nov 2015 (reference number 1.350.058).

\section{Consent for publication}

Written informed consent was obtained from the patient for publication of this case report and any accompanying images. A copy of the written consent is available for review by the Editor-in-Chief of this journal.

\section{Competing interests}

The authors declare that they have no competing interests.

\section{Publisher's Note}

Springer Nature remains neutral with regard to jurisdictional claims in published maps and institutional affiliations.

\section{Author details}

${ }^{1}$ Emergence Department, Irmandade da Santa Casa de Misericórdia de São Paulo, São Paulo, Brazil. ${ }^{2}$ Head \& Neck Surgery Discipline, Surgery

Department, Irmandade da Santa Casa de Misericórdia de São Paulo, São Paulo, Brazil. ${ }^{3}$ Faculty of Medical Sciences of Santa Casa de São Paulo, São Paulo, Brazil. 
Received: 23 September 2018 Accepted: 28 February 2019

Published online: 28 April 2019

\section{References}

1. Al-Ali M, Hefny A, Idris K, Abu-Zidan F. Cervical necrotizing fasciitis: an overlooked diagnosis of a fatal disease. Acta Otolaryngol. 2018;138:411-4.

2. Kantu S, Har-El G. Cervical necrotizing fasciitis. Ann Otol Rhinol Laryngol. 1997:106:965-70.

3. Mao J, Carron M, Fountain K, Stachler R, Yoo G, Mathog R, et al. Craniocervical necrotizing fasciitis with and without thoracic extension: management strategies and outcome. Am J Otolaryngol. 2009;30(1):17-23.

4. Suehara A, Gonçalves A, Alcadipani FA, Kavabata N, Menezes M. Deep neck infection: analysis of 80 cases. Braz J Otorhinolaryngol. 2008;74(2):253-9.

5. Deganello A, Gallo O, Gitti G, De Campora E. Necrotizing fasciitis of the neck associated with Lemierre syndrome. Acta Otorhinolaryngol Ital. 2009;29(3): 160-3.

6. Adoviča A, Veidere $L$, Ronis $M$, Sumeraga $G$. Deep neck infections: review of 263 cases. Otolaryngol Pol. 2017;71(5):37-42.

7. Suehara $A B$, et al. Descending necrotizing mediastinitis: analysis of 25 cases. Rev SBCCP. 2011;40(4):186-90.

8. Chen K, Chen J, Kuo S, Huang P, Hsu H, Lee J, et al. Descending necrotizing mediastinitis: a 10-year surgical experience in a single institution. J Thorac Cardiovasc Surg. 2008;136(1):191-8.

9. Tovi F, Fliss D, Zirkin H. Necrotizing soft-tissue infections in the head and neck. Laryngoscope. 1991;101(6):619-25.

10. Chen I, Hsu J, Dai Z. Management of descending necrotizing mediastinitis complicated with empyema by video-assisted thoracoscopic surgery. Pediatr Pulmonol. 2015;51(5):E17-20.

11. Lei W, Chang W, Shih S, Liu C, Shih C. Pyogenic liver abscess with Prevotella species and Fusobacterium necrophorum as causative pathogens in an immunocompetent patient. J Formos Med Assoc. 2009;108(3):253-7.

12. Memain N, Arvaniti K, Bruneel F, Leport C, Wolff M, Regnier B. Septic shock with liver abscess in an immunocompetence patient: presentation of an unusual Fusobacterium nucleatum infection. Presse Med. 2001;30:1777-9.

13. Crippin S, Wang K. An unrecognized etiology for pyogenic hepatic abscesses in normal hosts: dental disease. Am J Gastroenterol. 1992;87:1740-3.

14. Villanueva Rangel J, Bravo Martínez A, Segura Vimbela L, Villalobos Crespo E, Almazán Jiménez J. Mediastinitis necrotizante descendente secundaria a infección periodontal con extensión a pleura y peritoneo. reporte de un caso y revisión. MEDICRIT Revista de Medicina Crítica. 2009;6(1):38-45.

15. Arias-Chamorro B, Contreras-Morillo M, Acosta-Moyano A, Ruiz-Delgado F, Bermudo-Anino L, Valiente-Alvarez A. Multiple odontogenic abscesses: thoracic and abdomino-perineal extension in an immunocompetent patient. Med Oral Patol Oral Cir Bucal. 2011;16(6):772-5.

16. American Board of Internal Medicine (ABIM). ABIM laboratory test reference ranges. http://www.abim.org/ /media/ABIM\%20Public/Files/pdf/exam/ laboratory-reference-ranges.pdf. Accessed 15 Mar 2018.

17. Seer Yee ML, Abdul Rahim N, Ngah NA, Abdul Aziz YF, Subha S. Predicting neck abscess with contrast-enhanced computed tomography. Adv Otolaryngol. 2014;2014:896831.

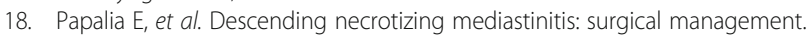
Eur J Cardiothorac Surg. 2001;20:739-42.

19. Lavini C, Natali P, Morandi U, Dallari S, Bergamini G. Descending necrotizing mediastinitis: diagnosis and surgical treatment. J Cardiovasc Surg. 2003; 44(5):655-60.

20. Almeida M, Tavares R, Mourão J, Carvalho J. Abcessos cervicais profundos de origem dentária - revisão de 105 casos. Rev Port Estomatol Med Dent Cir Maxilofac. 2013;54(4):197-202.

Ready to submit your research? Choose BMC and benefit from:

- fast, convenient online submission

- thorough peer review by experienced researchers in your field

- rapid publication on acceptance

- support for research data, including large and complex data types

- gold Open Access which fosters wider collaboration and increased citations

- maximum visibility for your research: over $100 \mathrm{M}$ website views per year

At BMC, research is always in progress.

Learn more biomedcentral.com/submissions 